International Journal of Applied Linguistics \& English Literature

ISSN 2200-3592 (Print), ISSN 2200-3452 (Online)

Vol. 1 No. 1; May 2012

\title{
Introducing Communicative Event As A Tool To Communicate Via the Medium Of Language: The Case of Job Advertisement
}

\author{
Minoo Pourfarhad \\ National University of Malaysia (UKM), Malaysia
}

Tel: 60-14-7179-516 E-mail: mnprfrhd@ yahoo.com

Received: 10-05- 2012

doi:10.7575/ijalel.v.1n.1p.104
Accepted: 28-05- 2012

Published: 31-05- 2012

URL: http://dx.doi.org/10.7575/ijalel.v.1n.1p.104

\begin{abstract}
This study is going to investigate the language style of classified advertisements of job vacancies in order to understand how advertisers manipulate language in convincing the job-seekers to apply for the advertised jobs. Furthermore, the study tries to examine the ways that advertisements' language may be concisely used to convey the meaning in the fewest words and avoid blurring the job seekers. To gain a clear picture of the form and content of job advertisements the views of (Lunde, 1974) and (Fairclough, 1989) are exploited to clarify how job advertisements may be perceived as a class of communicative events in order to communicate via the medium of language with potential job seekers and persuade them towards applying for the advertised jobs. The data for this qualitative study which came from the local English newspaper (Star) in the month of August were analyzed through content analysis. Being grounded in Lund (1974), who believes that an advertisement should: attract attention, arouse interests, stimulate desires, create conviction and get action, the sample advertisements were examined and the results revealed that all are in accordance with Lund's AIDEA formula. An analysis of the surface structure of the samples did not reveal how the basic structure of English sentences was adapted. The spaces allocated to these types of advertisements were so limited. Thus, the advertisers manipulate language in a way that they can convey their purposes with the use of minimum words. This may only be achieved by the use of the key words to convey the message and nominalizations.
\end{abstract}

Key words: concise language; language of communication; persuasive; conveying message; convincing language

\section{Introduction}

Local newspapers are replete with classified advertisement for job vacancies. Although some of the job advertisements are well elaborated, most of them are succinctly written and contain too much information which makes them somehow blurred or ambiguous to job seekers. Many candidates for the jobs need a better understanding of the job advertisements so that they can apply for the job with better insight.

Language is the medium of communication. As a result, job advertisers use language in order to encourage the job seekers to believe their claims (Jefkins , 2000). Since the space allocated to an advertisement is quite small in a newspaper, the advertisers need to be quite concise in using language for the communicational purpose. Besides, the language of advertisements in general and the language of job advertisements in particular need to be powerful. It is because the goal of an advertisement is for example to convince people to buy a product or to find services which may assist them to be more convenient with their life, or to respond to the advertisement (in this case, job candidates looking for jobs). Language can be exploited to persuade people to follow certain behavior (Fairclough, 1984), for example language may be used to encourage people towards performing specific acts. Thus, people in charge of advertisements use language effectively to convince people towards performing certain acts that may differ from purchasing specific products to spending their holidays in a particular place or to apply for an advertised job. There is always a possibility that people under the influence of advertisements act in certain ways which may not be in harmony with their benefits.

As a small scale study, this study has scrutinized the use and manipulation of language in job related classified advertisements and tried to investigate how advertisers exploit language in order to convince people that the claim of the advertisement is true, although sometimes it might not be the real truth.

1.1 Analysis of different definition of advertisements

An analysis of different definitions of advertisement would clarify the nature of advertisement and its relationship with social control and CDA.

Page $\mid 104$ 


\section{파망 \\ International Journal of Applied Linguistics \& English Literature \\ ISSN 2200-3592 (Print), ISSN 2200-3452 (Online)}

Vol. 1 No. 1; May 2012

Advertisement can be defined as a notification to public in order to extend information in the society with an emphasis on specific service or product (Harris and Seldon, 1962, in Senders \& Fryburger, 1976). This definition of advertisement is applicable to both industrial and commercial consumer advertisings (Vestergaard and Schroder, 1994). However, with the swift improvement of economy and the urgent needs for consumers, advertisement language shifted towards a persuasive and manipulative function (ibid).

Barret (1997, cited in Solomon, 1998) asserted that advertising is a necessity for supporting the marketing in order to impose influence through impression. (Burnett, 2000) defined advertisement as a paid communicational process from unknown supporter in order to encourage and affect audience through mass media. This definition has highlighted the persuasive aspect of advertisement rather than its informative aspect.

According to (Harrison, 2000) "the Institute of Practitioners in Advertising defined advertising as the most persuasive possible selling message to the right prospects for the product or service at the lowest possible cost". (p.5) In the quotation of the advertising the adjective "persuasive" is quite noticeable. It is in harmony with (Blackman, 2006) who asserted that job advertisements are a type of encouraging, convincing language and persuasive communication. It may be concluded that language of advertisement is supposed to be a "persuasive" language.

However, there are other researchers like (Steel , 1998) who presented another definition for the advertising. Steel considered advertisement as a series of easy words and actions for communicational purposes which lead consumers to think about the product that they are willing to get it. (Steel, 1998) added that consumers are intelligent enough to process any information-related to the product or services-that they are confronted with.

Similarly, (Jefkins, 2000) defines advertisement as an artistic work; therefore for postmodernism and post modern time it should be communication of realism. To Jefkins advertisements are capable of being meaningful as far as they are "corporate and credible". He contended that advertising cannot be performed by only: "cocking a snook at consumerism", (ibid).

The above analysis of literature reveals that researchers are not in agreement weather advertisements' language should be influential or not. Consequently, it is needed to carry out more analyses about the language use in advertisements.

\subsection{Appraising the function of advertising}

Investigation into the advertisement function will result in clarifying the initial function of advertising as a source of information which later evolved into a language of persuasion employed by advertisers for the benefits of both consumers and producers.

In the time that capitalism was not at its peak; for example the pre-capitalist era, advertising was employed as a means of informing consumers about existence of specific product (Vestergaard and Schroder, 1994). In post Second World War era when the economy of the western countries like the United States of America and European Western countries were booming, the goal of advertising had been changed considerably. Vestergaard and Schroder (1994) maintained that it was the era that the function of advertising changed from informative into persuasive. This was because capitalism became the most supreme hegemony in the market.

As a result of the improvement of economy and the swift growth of industries, the purpose of advertising shifted to be manipulative. Researchers in advertising asserted that the main function of advertising is the act of persuading consumers to buy the product (Barret, 1997). There are even researchers like (Solomon , 1988) that claimed the manipulation facet of advertisement is more important than its persuasion facet. Burnett (2000) claimed that the goal of the advertisement is to pay attention to the taste of ordinary people and simultaneously help the industries to produce goods in harmony with the consumers' tastes.

(Stuart, 1988, cited in Vestergaard and Schroder, 1994) underscored the provocative aspect of the advertisement and maintained advertisements should be attractive to the eyes of the consumers. At the extreme (Cook, 1992) emphasized on the emotive facet of the advertisement rather than its determinate aspect. This definition of advertisement will be resulted in lack of harmony between the factual performance of a piece of product and the consumer's belief constructed by the related advertisement.

As a result, advertisements not only aim at changing the consumers behavior in relation to purchasing goods, but also it tries to persuade people towards a specific lifestyle that is in harmony with producers benefits. But there are still researchers like (Rothschild, 1987) who believed those advertisements which are manipulative and have a tendency to direct the consumers towards buying cannot continue their existence in the free market for a long time. Therefore, it may be expressed that nowadays the function of advertisement is persuasive and manipulative. 
International Journal of Applied Linguistics \& English Literature

ISSN 2200-3592 (Print), ISSN 2200-3452 (Online)

Vol. 1 No. 1; May 2012

\subsection{Structure of the advertisement}

An analysis of advertisement's form is important. This is because such analysis provides some understanding of how an advertisement may attract the attention of consumers without having them to get involved in reading the advertisement like a piece of serious literature which requires close attention. (Vestergaard and Schroder, 1994) emphasized that an advertisement should be organized in a way that much of its message can be conveyed to the reader without reading it thoroughly. (Jefkins, 2000) addressed the structure of advertisement as having the highest importance. (Lund, 1974) presented five characteristics for the structure of the advertisement as follows: 1. Attract attention, 2. Arouse interest, 3. Stimulate desire, 4. Create conviction and 5. Get action.

The rationale of Lunde's outline for the structure of the advertisement is based on the reasoning that since people do not read the advertisement from beginning to end, its message should be conveyed by the form-rather than by the content-of the advertisement (Lunde, 1974). This will be achieved by including short words, short sentences and short paragraphs that assist to convey the message as conveniently as possible so that it can be absorbed by readers.

Consequently, the advertisers need to present their advertisements as clearly as possible and use language in a way that grasps people's attention (Jefkins, 2000). Furthermore, due to the limited space allocated to an advertisement in a newspaper, the advertisers can rarely use images to assist written language to convey their purpose. This shortcoming forces the advertisers to use encouraging words such as "Earn", "Enjoy", and "Find" in order to create a feeling of urgency in people (Jefkins, 2000).

As soon as the employed language attracts the attention of people, the next step is to encourage them to continue reading the whole advertisement. This also will be achieved by the use of persuasive as well as captive language such as "try to fulfill your dream" (Vestergaard and Schroder, 1994). In job advertisement such language unconsciously attracts the attention of job seekers and encourages them to continue reading the advertisement.

In order to force people towards certain behavior, the next step for an advertiser is to create a sense of wanting in readers. A potential job seeker who is confronted with an advertisement which presents them with the benefits of the job will feel a necessity for applying. It is why in job advertisements concise expressions referring to salary, wage or other benefits of the job are included.

As the final step, an advertiser should direct people towards a quick response to the advertisement; i.e. to apply for the advertised job. Vestergaard and Schroder (1994) contended that this may be achieved by two strategies: 1.By the use of imperative language and, 2. by the use of directive speech acts encourage people to perform a trial or ask for more information (ibid).

The above discussion tried to shed light on the structure of advertisements in general and the structure of job advertisement in particular.

\subsection{Advertisements and Critical Discourse Analysis (CDA)}

People in power try to form the beliefs of other people about the way that they do practice their life (Fairclough, 1989). This may be achieved by depicting people's life in advertisements' language (ibid). (Qualter, 1991) emphasized on the use of advertisements in establishing and interpreting the real world according to certain beliefs, values and ideologies that belong to people in power. Qualter highlighted the value of advertisements as a medium which function as an important establishment by which a society may be directed towards certain goals. Qualter contended that this may happen in an indirect way. By this definition of advertisements, it can be concluded that advertisements are functioning as manipulative establishments in the society. This view was formulated by Qualter as: "advertisements are seen as the source of authoritative guide to social behavior." The logic conclusion of the above discussion is that advertisements are sources of power that indirectly impose the advertisers' authority on the society; i.e. they direct people towards particular behaviors without any use of violence or authoritative command. This act of indirect imposing of power on the society takes place by discourse.

When organizations or individual persons are able to impose their authorities on people, it may be interpreted as a way to indirectly manipulate people towards certain behavior. (Fairclough, 1989) admitted this fact by asserting that there is a power behind the language which by it, one can control and direct others. He asserted that those who are at power will always try to maintain and intensify their power. And this can only be achieved by controlling the mass media (ibid). As a consequence, hegemony is achievable by manipulating people towards those specific behaviors which are favourable to individuals in positions of power. The manipulating of people and imposing hegemony on them can be achieved by the power which is in discourse.

It is also claimed that advertisements are employed to influence and shape the thoughts of people. Ingham (2000) discussed that advertisements not only used to inform people about particular services or products, but more 
International Journal of Applied Linguistics \& English Literature

ISSN 2200-3592 (Print), ISSN 2200-3452 (Online)

Vol. 1 No. 1; May 2012

importantly they are exploited to shape the mode of thinking of people as well as canalizing their social behavior.

As a result, Critical Discourse Analysis can be perceived as a powerful medium which is capable of shedding light on the hidden aspects of advertisements and can be employed to clarify how people may be persuaded towards particular courses of action. Language and society have an organic mutual connection that can shape and modify each other (Fairclough, 1989).

Language as a manipulating tool in the hands of owners of power is a medium of imposing hegemony, whereas expert in CDA can critically analyze language in order to show the hidden power behind it.

1.5 Statement of Problem

The language of the classified advertisement is a manifestation of types of discourse that is theorized as persuasive language (Vestergaard, T. \& Schroder, K., 1994). The purpose of such language is to communicate available products or services succinctly and inexpensively (Primentel, 2000). However, the spaces allocated to classified advertisements in the newspapers-in comparison to other discourses-are very limited and advertisers cannot use the elaborated language of other discourses, for example editorials (ibid). Lopes (1993) maintained that advertisers employ the fewest number of words to convey the meaning. As a result, the advertisers are restricted in their choice of language and there is a possibility that some necessary information for job seekers is left out in their advertisements. Which this in turns may lead to the possibility that some of those who are addressed by the advertisement; here jobseekers, will be misguided or will not become fully aware of the aims of the advertisement, or feel that the claim of the advertisement is not compatible with the real world situation. In other words, when potential job seekers find an advertisement they make a mental image of their future career. But when they confront with the real situation they may be become disappointed because there is a possibility that the claim of the advertisement is not exactly the same as the real situation.

One may say that while advertisements are not fully capable of conveying the necessary information, what is the point of presenting people with materials that can be misleading? However, there are researchers such as (Jefkins, 2000) who emphasized the importance of the advertisements in the modern life. Therefore, the study investigates the use of language in the job related advertisements in order to understand how advertisers exploit language to convince people towards certain behavior and besides, how the possibility of misguiding the job seekers can be minimized. Consequently, it may lead to the refinement of the language of job advertisers and better insight of job seekers towards their future career as well.

1.6 Theoretical framework of the study

To gain a clear picture of the form and content of job advertisements the views of (Lunde, 1974) and (Fairclough ,1989) are exploited to clarify how job advertisements may be perceived as a class of communicative events in order to communicate via the medium of language with potential job seekers and persuade them towards applying for the advertised jobs.

The views of (Lunde, 1974) are used to as a basis for discussion about the structure of job advertisements as a type of written discourse. Besides (Fairclough, 1989) maintained that advertisements are media discourses since they employ language in connection to society. The Fairclough's views provide a second basis to investigate the content of job advertisements as a genre that comprises specific communicative purposes; for example to persuade potential job seekers to apply for the advertised jobs.

1.7 Objectives of the study

The study is going to investigate the language style of classified advertisements of job vacancies in order to understand how advertisers manipulate language in convincing the job-seekers to apply for the advertised jobs. Furthermore, the study tries to examine the ways that advertisements' language may be concisely used to convey the meaning in the fewest words and avoid blurring the job seekers. Therefore, the study aimed at:

1. To discuss the structure of classified job advertisements in relation to Lunde's views about the forms of advertisements (Lund, 1974).

2. To investigate the techniques which may be employed in order to concisely convey meaning in the classified advertisements for job seekers in relation to the theoretical framework presented by (Fairclough, 1989. 1999).

1.8 Research Questions

1. What are the major characteristics of an advertisement for job vacancy?

2. How the language of advertisements is concisely employed in order to convey the meaning in the fewest words?

Page | 107 
International Journal of Applied Linguistics \& English Literature

ISSN 2200-3592 (Print), ISSN 2200-3452 (Online)

Vol. 1 No. 1; May 2012

\section{Methodology}

Since the researcher is more interested in describing the data in order to explicitly address the research questions, a qualitative research design is more adaptable for this study. Like any other basic qualitative research study, the researcher is the main instrument for the data collection. Qualitative data collection method of this study is the content analysis of the advertisements in the local English newspaper (Star) in the month of August 2010. Data collection procedure involves:

1. Locate five job-related classified advertisements in the English local newspaper (Star) which were chosen randomly in the month August 2010.

2. All the chosen job related advertisements were analyzed in relation to the frameworks discussed under the theoretical frame work of the study; i.e. the proposed frameworks for advertisements by (Lund, 1974), and the views of (Fairclough, 1989 \& 1999) in terms of language and power.

3. Data analysis procedure was conducted by attempts to analyze if the selected advertisements are adaptable with theories; i.e. :

a. Are they in harmony with Lund (1974); i.e. do they attract attention, arouse interest, stimulate desire, create conviction, and get action?

b. How the selected advertisements employ the written language as a particular discourse in relation to the society based on Fairclough's $(1984,1999)$ views.

\subsection{Research Design}

As it was discussed before, the researcher was more interested in describing the collected data as well as the results of the data analysis in order to investigate and pinpoint the language of advertisements; it is why a qualitative methodology was adapted for the study. The researcher attempted to interpret the data based upon the theoretical framework which was explained before.

\subsection{Data Collection Procedure}

Askehave (2010) contended: "the task of business communication is to find the appropriate words to pique the curiosity of the desired potential workers and encourage them to continue through the application process." Askehave's assertion is quite compatible with the classic definitions of advertisements which were briefly surveyed in literature review chapter. To make a content analysis of the classified job advertisements and to understand how language of them is in harmony with classic definitions of advertisements, five job-related classified advertisements were chosen randomly from the English local newspaper (Star) in the month of August of the year 2010.

\subsection{Data Analysis Procedure}

As the first step in data analysis procedure, attempt was made to understand how the structures of the advertisements are in harmony with the proposed advertisement structure by (Lunde, 1974). Lund proposed five criteria to organize an advertisement. He clarified that an advertisement should: 1 . Attract attention, 2. Arouse interest, 3. Stimulate desire, 4. Create conviction, and finally, 5. Get action.

The next step of data analysis was the proposed approach by (Fairclough, 1984 \& 1999). Fairclough described a text in terms of having "experiential, rational and expressive" values.

The experiential value is the way that the text producer experiences the world and presents it in the form of their text (Fairclough, 1984 \&1999). As a small scale study, only experiential values of the advertisements in terms of the grammatical features as well as choice of words of the classified advertisements were examined.

\section{Results and Discussion}

This part was focused on the analysis of the samples of the classified advertisements. In order to answer the research questions: first the samples were analyzed to see whether they are in harmony with the AIDCA formula (Lund, 1974); i.e. Attention, Interest, Desire, Conviction, Action, second the samples were analyzed in relation to the forms of the texts. Fairclough $(1984,1990)$ distinguished six main levels of a text interpretation. Two levels of interpretations are related to context. Four levels of interpretations are in relation to text. This study looked at text of classified advertisements in terms of grammar and vocabulary to clarify how advertisers have employed language concisely in order to encourage potential job-seekers towards certain behavior; i.e. applying for the advertised job.

Analyzing samples to answer research question 1: What are the major characteristics of an advertisement for job vacancy?

Page $\mid 108$ 
International Journal of Applied Linguistics \& English Literature

ISSN 2200-3592 (Print), ISSN 2200-3452 (Online)

Vol. 1 No. 1; May 2012

In sample 1 in order to attract attention the phrase "Immediate Vacancies" is used, the phrases "Admin Executive: RM 2300-3.000, Admin Assistance: 1.800-2.200" simultaneously arouses interest and stimulate desire, "Please Call 03-21266 1366" gets action. In order to convince the reader the Benefits are included as well.

\section{Sample 1}

\section{IMMEDIATE VACANCIES}

ADMIN EXECUTIVE: 2.300-3.000,ADMIN ASSISTANCE: 1.800-2.200

Requirements: Diploma/Degree holders (any field), Fresh graduate are encouraged to apply, with or without experience, Age bellow 30 is preferable

Benefits: 5 working days, Carrere advancement Opportunity, nearby public transportation, Annual Leave \& bonus, Company trips (local/Overseas)

Please call: E., MALIK/CIK HANIM (03-2166 1366)

Table 1 summarized the results of the analysis to investigate if the samples are in harmony with AIDCA formula (Lund, 1974):

\begin{tabular}{|c|c|c|c|c|c|}
\hline structure of an advertisement & sample 1 & sample 2 & sample 3 & sample 4 & sample 5 \\
\hline \multicolumn{6}{|l|}{ attract attention } \\
\hline \multicolumn{6}{|l|}{ arouse Interest } \\
\hline \multicolumn{6}{|l|}{ stimulate desire } \\
\hline \multicolumn{6}{|l|}{ create conviction } \\
\hline get attention & & & & & \\
\hline
\end{tabular}

Analyzing the samples in order to answer research question 2: How the language of advertisements is concisely employed in order to convey the meaning in the fewest words?

In the second level of analysis, briefly the grammar of simple sentences in English is examined. Three types of simple sentences in English are identified:

1. Subject + Verb $(\mathrm{S}$ V)

2. Subject + Verb + Object $(\mathrm{S}$ V O $)$

3. Subject + Verb + Complement $(\mathrm{S}$ V C)

Each type may typically be the manifestation of a specific process. Type two (S V O) may convey Actions. Type one (S V) and three (S V C) may convey Events and attributions respectively.

An analysis of the surface structure of the samples (answer to research question 1) did not reveal how the basic structure of English sentences is adapted. It was discussed already that the spaces allocated to these type advertisements are so limited. Thus, the advertisers manipulate language in a way that with the use of minimum words they can convey their purpose. This only may be achieved by the use of the key words to convey the message. Besides, the charge imposed on classified advertisements will be based upon the number of words used in each advertisement. As a result, the less words included in an advertisement, the less the cost will be. Consequently, the classified advertisements are manipulated in such a way that only key words are used. The use of the key words in advertisements solves the problems of charge and restricted allocated space to advertisements. But there is another problem that the advertisement should be capable of informing the job-seekers so that they can perceive an image of the job that would be as close as to the real nature of the job. Under other circumstances; i.e. when the job specifications are not in harmony with the related advertisement, the potential candidate for the job may feel that they are cheated or at least misguided.

This takes the analysis directly to the employed strategies by the advertisers. The advertisers, based on the analyzed samples in this study, excluded the names as well as the positions of the jobs for the potential job

Page | 109 
International Journal of Applied Linguistics \& English Literature

ISSN 2200-3592 (Print), ISSN 2200-3452 (Online)

Vol. 1 No. 1; May 2012

seekers. In occasions that the name of the job is included, the details of the job are excluded. Sample 2 is an evidence of the above discussion:

Sample 2

\begin{tabular}{|r|}
\hline PHARMACISTS ARE WANTED \\
\\
,$\quad$ Incentive \\
,$\quad$ Profit Sharing \\
Good Benefits \\
Care Farmasi \\
No. 5, Jalan SG/3, Taman Sri Gombak, \\
68100 Batu Caves, Selangor \\
Tel:03-61856682
\end{tabular}

In the above sample, although the name of the job is mentioned; for example Pharmacist, there is no description of the job. A potential job seeker may be confronted with the question: "What are the specifications of the job?" This may be interpreted as a way that language is exploited in order to receive the maximum feedbacks; i.e. the maximum number of applicants, whereas the minimum of information is provided. This assists the owner of the industry to interview a large number of candidates in order to select the best one(s) who fit(s) the job.

Another strategy exploited by the advertisers is to put the job seekers in the position of the subject of the advertisement. In spite of the fact that no clear simple sentences used in such advertisements, a careful analysis revealed that the imperative sentences were used which in turn led the researcher to this finding that the used verbs are expressions of action. In the expressions of actions there are two elements of agent and patient. An analysis of sample 3 provides an evidence for the above discussion:

Sample 3

\section{ENHANCE YOUR EMPLOYIBILITY}

Join our Graduate Employability Program to enhance your industry-specific skills.

Enjoy RM 500 allowance per month

Get free Training sponsored by the Ministry of Human Resources

Call 012-699 5655 Mr. Thinahran

Note: open to diploma/degree graduate only (unemployed for at least three month)

If the two imperative sentences in the advertisement are rewritten in simple sentences, the two following sentences will result:

\begin{tabular}{|c|c|c|c|}
\hline You & can join & our graduate employability program & to enhance your industry-specific skills \\
\hline S & V & $\mathrm{O}$ & Adjunct \\
\hline$\underline{\text { You }}$ & $\underline{\text { can get }}$ & free training & the Ministry of Human Resources. \\
\hline $\mathrm{S}$ & V & $\mathrm{O}$ & Adjunct \\
\hline
\end{tabular}

In the above examples, the job seekers or the readers are the agents and the benefits of the job are perceived as patients. It seems if all the imperatives in the samples change into simple sentences, the process of action, subject, and agent will be the prominent in the advertisements' texts. It may be concluded that the advertisers are

Page $\mid 110$ 
International Journal of Applied Linguistics \& English Literature

ISSN 2200-3592 (Print), ISSN 2200-3452 (Online)

Vol. 1 No. 1; May 2012

persuading the job-seekers to perceive themselves as the subjects of the sentences. As soon as the job-seekers perceive themselves as the subjects of the sentences, they can conclude that they will benefit from the advantages of the job.

Sample 4

\begin{tabular}{|c|}
\hline TELE-SALES CLERK \\
(MENARE KUALA LUMPUR) \\
FULL TIME \\
Basic Salary RM 1200 \\
Commission RM 1000-3000 Weekly \\
Incentive Trips to Local and Overseas \\
Full Training Provided in Menara KL \\
No experience Needed \\
\hline
\end{tabular}

If one simple sentence from sample four is rewritten in a simple sentence the result will be:

Original sentence in sample four: Basic salary RM 1200

Rewritten sentence: Your basic salary $\quad \underline{\text { will be }}$

$\underline{\text { RM } 1200 .}$.

$\mathrm{S}$

$\mathrm{V}$

$\mathrm{O}$

The above discussion about sample three is applicable to extracted sentence from sample four. That the reader can conclude if they apply for the job, their basic salary will be RM 1200.

The logic conclusion is that the advertiser is persuading the readers that they will benefit from the job if they apply for it.

3.1Use of nominalization

A nominalization is a process in which a sentence is reduced into a noun. This procedure may be employed to put the readers in the position of the agent (Fairclough, 1989).

It was found that nominalization process is used in all five sample advertisements. In sample five the nominalization process is used repeatedly in order to convince the readers to perceive themselves as the agent for the action.

Sample 5

\section{ELECTRICAL ENGINEER}

Email: wongss@projalma.com.my

Degree/Diploma in Electrical Engineering

Tel: 03-6753355 Fax; 03-62753288

Fresh graduated are encouraged to apply

GENERAL CLERK

SPM \& above

TECHNICAL TRAINEE

Good writing \& verbal communication skills in English and Chinese

DRAUGHTSPERSON

TECHNICAL ASSISTANT

Fresh graduated are encouraged to apply

STORE KEEPER (Based in Bt. Gajah, Perk)

Interested candidates are invited to submit their resume to:

Lot 11 \& 12 Jalan 2, Taman Kepong,

52100 Kepong, KL (beside Kepong central) 
International Journal of Applied Linguistics \& English Literature

ISSN 2200-3592 (Print), ISSN 2200-3452 (Online)

Vol. 1 No. 1; May 2012

\begin{abstract}
4. Summary and Conclusion
Classified job advertisement can be considered as a particular written discourse that employs language in order to persuade people towards certain acts; for example applying for the advertised job. In producing job-advertisements, like any other types of classified advertisements, advertisers are confronted with the problem of limited allocated space to their advertisement. Consequently, the language of classified advertisements in general and job-advertisements in particular, is a concise language.

This study investigated the classified job advertisements in order to understand how the language of advertisements is concisely used to persuade the potential job seeker to apply for the advertised job. Besides, the studies hopefully aimed at clarifying the language of job advertisements in order to assist the job advertisers improve their product so that can convey the maximum message in the minimum space. On the other hand, the study tried to help the potential job-seekers to gain a better insight of the classified job-advertisements so that they may apply for their future career with better awareness. This will hopefully help the potential job-seekers not to feel that they are cheated or misbehaved by the advertisements.

In order to carry out the study, five classified job advertisements were selected randomly from the English newspaper (Star) in the month August of the year 2010. In relation to the theoretical framework suggested by Lund (1975), that believes an advertisement should: attract attention, arouse interests, stimulate desires, create conviction and get action, the sample advertisements were examined and the result was arranged in a table based on AIDEA formula.

In the second layer of the analysis, under the theoretical framework of Fairclough $(1984,1990)$ the samples were examined to understand how the sentence structure of the samples is in agreement with structure of English simple sentences. Besides attempt was given to clarify how nominalization was used to concisely employ and manipulate the persuasive language of the classified job advertisements.
\end{abstract}

\title{
References
}

Askehave, I. (2010). Communicating Leadership: A Discourse Analytical Perspective on the Job Advertisement. Journal of Business Communication 47 (3): 313-345.

Baran, S.j. \& Davies, D.K. (1992). Mass Communication in the Mass Media. London: Macmillan Press Ltd. Blackman, A. (2006). Graduating students' responses to recruitment advertisements. Journal of Business Communication 43(4), 367-388.

Burnett, M. (2000). Advertising: Principles and Practice. Pearson.

Cook, G. (1992). The Discourse of Advertising. London: Rutledge.

Fairclough, N. (1984). Language and power. United Kingdom: Longman.

Fairclough, N. (1989). Language and Power. United Kingdom: Longman.

Fairclough, N. (1999). Critical Discourse Analysis, London: Longman.

Harrison, S. (2000). Public Relations. Second edition. London: Thomas Learning.

Ingham, H. (2000). What Value is there in Studying Advertisements. Retrieved on September 28, 2010 from http://www/aber.ac.ukmedia/stdent/hin5501.html.

Jefkins, F. (2000). Advertising (4th edition). England: Pearson Education Limited.

Lopes, D. M. (1993). The Construction of Meaning in Advertising Language: The rules of the game, UMI Pro Quest Digital Dissertation 55 (03), 703, 1999

Lunde, J. V. (1974). News Advertising. New York: Prentice Hall, Inc.

Primentel, J. J. Jr. (2000). Sociolinguistic Reflection of Privatization and Globalization: The Arabic of Egyptian Newspaper Advertisements, Unpublished Doctoral Dissertation. Michigan: University of Mishigan.

Qualter, T. H. (1991). Advertising and democracy in the Mass Media. London: The Macmillan Press Ltd.

Rothschild, M. L. (1987). Advertising. Toronto: D. C. HEATH AND COMPANY.

Sanders \& Fryburger (1976). Advertising Theory and Practice. Illinois: IRWN, INC.

Solomon, (1988). Master of Desire: The Culture of American Advertising. Retrieved on September 10, 2010 from http://sare20-/unixlab.virginia.edu/ams/enmr101/solmon.html

Steel, J. (1998). Truth, Lies and Advertising: the Art of Account Planning. John Wiley \& Sons.

Vestergaard, T. \& Schroder, K. (1994). The Language of advertising. Oxford: Blackwell. 